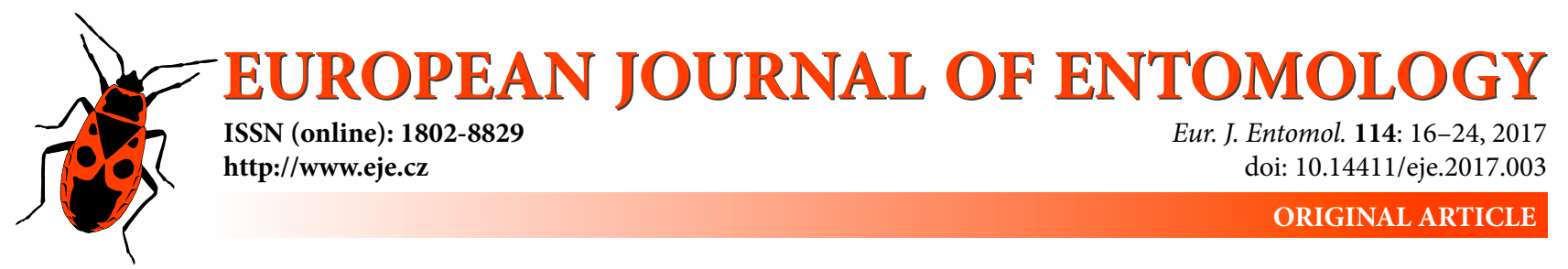

\title{
Polygalacturonase gene expression and enzymatic activity in salivary glands of laboratory reared and wild populations of Lygus lineolaris (Hemiptera: Miridae)
}

\author{
Daniel fleming, Natraj KRISHNAN and Fred MUSSER \\ Department of Biochemistry, Molecular Biology, Entomology, and Plant Pathology, Mississippi State University, Box 9775 , \\ 100 Old Highway 12, Mississippi State, MS 39762, USA, e-mails: def18@entomology.msstate.edu, \\ nkrishnan@entomology.msstate.edu,fmusser@entomology.msstate.edu
}

Key words. Hemiptera, Miridae, cotton, Lygus lineolaris, gene expression, polygalacturonase, salivary gland, enzyme activity

\begin{abstract}
Lygus lineolaris (Palisot de Beauvois, 1818) (tarnished plant bug) is a serious pest of cotton (Gossypium hirsutum L.) in the Delta region as compared to cotton in the Hills region of the state of Mississippi in USA. The reason for this is unclear but it was hypothesized that the plant cell wall degrading polygalacturonase enzyme system in the salivary glands of $L$. lineolaris from the Delta could be better adapted for cotton, which is grown more predominantly in the Delta region than in the Hills region. Expression analysis of three primary polygalacturonase genes (LIPG1, LIPG2 and LIPG3) was conducted in laboratory reared and field collected populations of $L$. lineolaris. Assay of polygalacturonase enzyme activity was also conducted to compare wild collected populations. Initial laboratory and field data revealed gene expression differences in sex, age, region, and host plant which guided the direction of our subsequent study during 2013 and 2014. Based on the results of this study, we propose that the three genes studied may not be reflective of the entire polygalacturonase enzyme system and may not be solely responsible for the observed adaptation of $L$. lineolaris to cotton in the Delta region than in the Hills region. Analyses also revealed that the expression of the three targeted polygalacturonase genes was affected by the host plant from which the insects were collected and that adults had higher polygalacturonase expression than nymphs. Taken together, our results provide strong evidence for developmental stage specific and host plant based change in expression of PG genes in the salivary glands of $L$. lineolaris. This, however, was not reflected in total polygalacturonase enzyme activity which was not significantly different between regions, hosts, sex, or developmental stage.
\end{abstract}

\section{INTRODUCTION}

Lygus lineolaris (Palisot de Beauvois, 1818) (Hemiptera: Miridae), the tarnished plant bug, is a major pest of cotton (Gossypium hirsutum L.) in Mississippi in the USA. Mississippi cotton producers made an average of 4.3 insecticide applications for control of $L$. lineolaris each year from 2012 to 2014 at a cost of approximately $\$ 140$ per ha per year (Williams, 2012-2014). Since 1986, the cotton yield losses due to pest insects for Mississippi have been reported separately for two regions, the Delta and the Hills. The Delta (Alluvial plain) is the region of western Mississippi that is the flood plain of the Mississippi and Yazoo rivers and includes the area west of the Loess Bluffs (Fig. 1). The Hills region is the remainder of the state, but, for the purposes of this study, consists of the North Central Hills, Flatwoods, Pontotoc Ridge, Black Prairie, and Tombigbee Hills (Fig. 1). The Delta is intensively farmed and has less non-cultivated areas than the Hills region, which typically has smaller fields with adjacent non-cultivated areas (Fry et al., 2011). Cotton yield loss and cost of control of L. line- olaris is dissimilar between Mississippi's two main cotton growing regions (Williams, 1986-2014). The estimated number of insecticide applications targeting $L$. lineolaris has been approximately 2.6-fold higher in the Delta than in the Hills almost every year (Williams, 1986-2014), but the reason for these differences is not fully understood.

Biological differences between populations of $L$. lineolaris collected in Mississippi have been reported from laboratory studies (Adams et al., 2014). The number of days for $L$. lineolaris development to adulthood when feeding on cotton was 1.67 days longer for colonies collected from the Hills than for those collected from the Delta $(\mathrm{p}<0.05)$, while differences in developmental time were not observed for those fed on artificial diet. Additionally, females from colonies collected from the Delta laid 1.09 more eggs per day than females from colonies collected from the Hills ( $p$ $<0.05$ ). Shorter developmental time and higher fecundity in Delta colonies indicates that some populations of $L$. lineolaris may be more specialized for development on cotton and that the fecundity of some L. lineolaris populations 


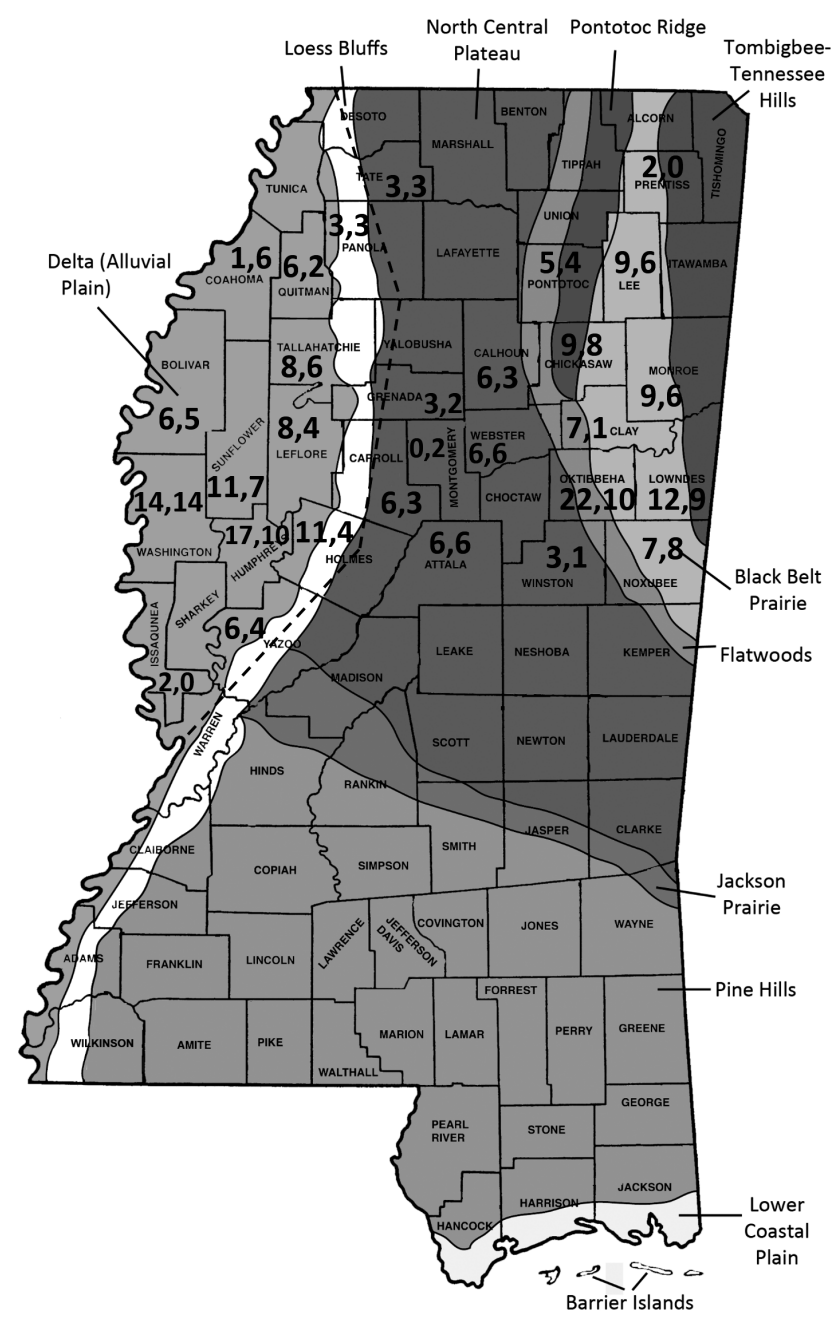

Fig. 1. Map showing the geographic regions of Mississippi and the total number of cohorts of male, female, and nymph $L$. lineolaris collected per county during 2013-2014 for purposes of gene expression and enzyme activity (represented as gene expression enzyme activity). Numbers to the left of the dashed line represent populations collected from the Delta (alluvial plain) region, while numbers to the right of the line were collected from any of the geographic regions east of the Loess Bluffs.

are different. These biological differences between populations may indicate that some populations may be better adapted to some hosts than others. A more recent laboratory study using wild caught populations failed to find any significant biological differences, including differences for developmental time and fecundity, between Delta and Hills populations (Fleming et al., 2015b). The reason for this is unknown, but this finding does not exclude the possibility of other biological explanations for the phenomenon of $L$. lineolaris being more damaging in the Delta than the Hills region.

A biological basis for possible population adaptations to hosts has not been identified. In phytophagous insects such as Lygus sp., which primarily feed directly on plant tissues using piercing-sucking mouth parts, the saliva plays a crucial role in extra-oral digestion of food. This mode of feeding has been described as "lacerate and flush", whereby the flexible maxillae penetrate the plant tissues, destroying and breaking cell wall components and tissue by releas- ing large amount of saliva which allows establishment of the pest on host plant(s) (Miles, 1972). The role of pectin degrading enzymes (polygalacturonases, $\mathrm{PG}$ ) in the saliva of Lygus bugs was recognized more than four decades ago (Strong \& Kruitwagen, 1968, 1970). The direct effects of PG during feeding of $L$. lineolaris on cotton are square abscission, necrosis at the wound site, deformation of squares and bolls, aborted embryos, and reduced or altered vegetative growth (Strong \& Kruitwagen, 1970). At the time of initiation of the current project, studies injecting extracted Lygus saliva to host plant tissue revealed that the PGs in saliva causes Lygus-like damage in plants (Shackel et al., 2005; Celorio-Mancera et al., 2008), and that at least four PG genes (LlPG1, LlPG2, LlPG3, and LlPG4) were present in the saliva of $L$. lineolaris (Allen, 2007; Allen \& Mertens, 2008; Walker \& Allen, 2010). Of these, at least one of the genes (LlPG1) appears to be regulated based on diet (Walker \& Allen, 2010). Recent transcriptomic data of L. lineolaris salivary glands indicate that there are at least 28 different $\mathrm{PG}$ proteins and they can be grouped into 8 different PG clades phylogenetically (Showmaker et al., 2016). Further a cDNA sequencing analysis study revealed the presence of 45 PGs in L. lineolaris saliva that clustered into 6 clades similar to that reported in Apolygus lucorum (Meyer-Dür, 1843) saliva (Zhang et al., 2015; Zhu et al., 2016). However, despite reports of the presence of PG proteins (which represent both endo and exo-PGs) little else is known about the functions of PG genes, the PG enzyme, and how they are regulated. A hypothesized mechanism for the reported biological differences in L. lineolaris populations from the Delta and Hills region of Mississippi may be differences in the polygalacturonase enzyme system of $L$. lineolaris saliva. If PG is a mechanism driving the biological differences observed in L. lineolaris populations then investigations of this system may reveal some PG genes are important for specific hosts, especially cotton, and if regional differences in the damage to cotton can be attributed to population differences in the PG system.

Further knowledge of the PG system could support work toward understanding $L$. lineolaris-plant interactions that may lead to development of PG resistant plants through traditional plant breeding or genetic modification. Research using dsRNA supplied through genetically modified plants or in diet has shown that insect growth, feeding, development, metabolism of insecticides and plant defense compounds, fitness, and survival can be inhibited or reduced as a result of RNA interference (Baum et al., 2007; Mao et al., 2007; Zhao et al., 2008; Zhou et al., 2008; Bautista et al., 2009), thus inhibition of PG damage or feeding by $L$. lineolaris may be possible through RNAi. Walker \& Allen (2010) showed that expression of LlPG1 was the highest expressed PG gene for $L$. lineolaris fed cotton and could be inhibited up to $80 \%$ with the use of dsRNA, thus targeting this specific gene may reduce damage to cotton. Also, polygalacturonase inhibiting proteins (PGIP) exist in plants and their inhibition of PG can be specific to the source of the enzyme (Cervone et al., 1987; Toubart et al., 1992; Bergmann et al., 1994; Powell et al., 2000; D'Ovidio et al., 
2004; Joubert et al., 2006; Ferrari et al., 2011; Akhgari et al., 2012). It may therefore be possible to selectively breed host plants with higher PGIPs depending on the specific PG genes activated in Lygus saliva for efficient feeding. Thus, a fundamental understanding of the regulation of PG gene expression in the insects salivary gland is vital.

Based on the regional differences of the economic impact of $L$. lineolaris to cotton and to gain fundamental insights of the PG system in L. lineolaris, a series of experiments were undertaken to look at changes in PG gene expression of L. lineolaris based on the regional location of the host population, plants from which the collection was made, age of the adult, developmental stage of the insect and sex. Only three well characterized PG genes were targeted in this study as a first step to understanding the differences in PG gene expression and enzyme activity between regional populations. It was hypothesized that such differences may indicate a potential biotype or sibling species shift and may help explain the higher severity of damage that occurs to cotton in the Mississippi Delta.

\section{MATERIALS AND METHODS}

\section{Insects and collections}

\section{Laboratory reared colonies}

Sampling for sex and age comparisons. Lygus lineolaris adults from a colony reared at the Mississippi State University Insect Rearing Center since 2007 were used to compare expression of PG genes in male and female L. lineolaris adults at four different ages. The colony was housed in a rearing facility with a $16 \mathrm{~L}: 8 \mathrm{D}$ cycle that is kept at $26.7^{\circ} \mathrm{C}$ with approximately 60 $70 \%$ relative humidity. Insects were fed an oligidic artificial diet (Cohen, 2000) and offered carrageenan gel packs for oviposition. Insects were aspirated from containers of the parent colony containing approximately one-day-old, five-day-old, ten-day-old, and fifteen-day-old adults. Ten adults of each sex at each age were removed for each treatment, and this was repeated on each of three days (three replicates). Males and females were separated by observing the presence or absence of the ovipositor on the ventral surface of the abdomen (Schuh \& Slater, 1995). Insects that were removed from the parent colonies were placed in scintillation vials in $\mathrm{a}-20^{\circ} \mathrm{C}$ freezer to kill them and the following day they were transferred to $1.5 \mathrm{ml}$ DNase and RNase free microcentrifuge tubes and placed in a $-80^{\circ} \mathrm{C}$ freezer for storage until further processing.

Sampling for nymph and adult comparisons. Lygus lineolaris adults and nymphs from a colony collected in 2012 and housed for approximately four generations at the Mississippi State University Insect Rearing Center under the same conditions as the previously mentioned colony were used to compare PG gene expression in adults and nymphs. Insects were aspirated from each of three cohorts (three replicates) from containers of old adults ( $>10$ days) young adults ( $<5$ days) and nymphs ( 5 th instar) and placed into scintillation vials in a $-20^{\circ} \mathrm{C}$ freezer overnight to kill them. The following day the insects were placed into $1.5 \mathrm{ml}$ DNase and RNase free micro-centrifuge tubes for storage in $\mathrm{a}-80^{\circ} \mathrm{C}$ freezer until further processing.

\section{Wild collected populations}

2012 L. lineolaris field collections. Lygus lineolaris adults were collected from 30 locations (five locations per host per region) in the Delta and Hills regions of Mississippi from cotton (Gossypium hirsutum L.), horseweed (Conyza canadensis
(L.) Cronquist), and pigweed (Amaranthus sp.) in the summer of 2012. Collections were made with a $38 \mathrm{~cm}$ sweep net, insects were placed into plastic tubs to be separated from other insects and sweeping trash and then aspirated into cricket cages. Reproductive plant tissue from the host plants was placed in the cages and the cages were transported back to the laboratory in a cooler containing ice packs. Cages were placed in $\mathrm{a}-20^{\circ} \mathrm{C}$ freezer overnight to kill the insects. The following day, ten insects from each host and location were placed into scintillation vials and stored in a $-80^{\circ} \mathrm{C}$ freezer until further processing.

2013-2014 field collections. To further explore data that was collected from laboratory reared insects and the wild population from 2012, a two year study using wild adult and nymphal L. lineolaris collected during 2013 and 2014 was conducted to evaluate PG gene expression and enzyme activity. Adults and fifth instar nymphs of $L$. lineolaris were collected from crimson clover (Trifolium incarnatum L.), cotton, fleabane (Erigeron sp.), horseweed, and pigweed in the late Spring (primarily clover and fleabane), Summer (primarily cotton, horseweed, and pigweed), and early Fall (primarily pigweed) of 2013 and 2014. The number of locations (replicates) collected from ranged from four to ten for any sex, developmental stage and host combination (Fig. 1). Insects were collected, transported and killed similar to those in the 2012 study. The day following collection, insects were sorted by sex and developmental stage (male, female, 5th instar nymph) and ten insects of each sex anddevelopmental stage from each host and location were placed into scintillation vials. Vials were then placed into a $-80^{\circ} \mathrm{C}$ freezer until further processing for gene expression or enzyme assay.

\section{Dissection and isolation of salivary glands}

Insects in all experiments were surface sterilized by dipping each insect into $70 \%$ ethyl alcohol and then rinsed by dipping each insect into distilled water. Insects were then air dried under a laminar flow hood and sorted to be used either to measure gene expression or enzyme activity. Salivary glands were extracted by removing the head and prothorax by pinching the projection of the prothoracic notum and pulling forward thus exposing the salivary glands. Ten pairs of salivary glands for each sample were placed in $1.5 \mathrm{ml}$ DNase and RNase free micro-centrifuge vials, and then placed in a $-80^{\circ} \mathrm{C}$ freezer until further processing for gene expression. For the 2013-2014 wild L. lineolaris study, ten salivary glands for each sample were placed in micro-centrifuge tubes and stored in a $-20^{\circ} \mathrm{C}$ freezer until further processing for enzyme activity.

\section{Gene expression analysis}

All insects from all experiments, with the exception of those from the 2013-2014 experiment that were used to assay enzyme activity, were employed for gene expression analysis using quantitative real-time polymerase chain reaction. Total RNA was extracted from salivary glands (ten insects pooled per sample) using Tri Reagent (Sigma, St. Louis, MO, USA). The samples were treated with Takara Recombinant DNase I (Clontech Laboratories Inc., Mountain View, CA, USA). Synthesis of cDNA was achieved with the iScript cDNA synthesis kit (BioRad, Hercules, CA, USA). Quantitative real-time PCR (qRT-PCR) was performed on the Eppendorf realplex ${ }^{2}$ Mastercycler (Eppendorf, USA) under the following thermal cycling conditions: $95^{\circ} \mathrm{C}$ for 10 min then perform 45 cycles at $95^{\circ} \mathrm{C}$ for $15 \mathrm{~s}, 59^{\circ} \mathrm{C}$ for $20 \mathrm{~s}$, and $72^{\circ} \mathrm{C}$ for $30 \mathrm{~s}$, with a dissociation curve step running at $95^{\circ} \mathrm{C}$ for $15 \mathrm{~s}$ then $60^{\circ} \mathrm{C}$ for $15 \mathrm{~s}$, and then ramped for $20 \mathrm{~min}$ up to $95^{\circ} \mathrm{C}$ and hold for $15 \mathrm{~s}$. Every reaction contained Power SYBR Green (Applied Biosystems), 10 ng cDNA, and $400 \mathrm{nM}$ primers. Primer sequences are given in Table 1 . The primers were checked 
Table 1. List of primers and their sequences used.

\begin{tabular}{lll}
\hline Gene & Forward primer $\left(5^{`}-3^{`}\right)$ & Reverse primer $\left(5^{`}{ }^{`} 3^{`}\right)$ \\
\hline LIPG1 & GGG GAG AGA CTG GGG CGA TT & GAA CGG GGT CGC ATC ACC TG \\
LIPG2 & AGA ATA CTC CAG CCC CTT GC & GTG ACG AAG CAG TCG TCT TG \\
LIPG3 & GTC ATC ATT GCC AAC AGC AC & TGC CAT TCAACA GGG TCT TG \\
rp/6 & TGC TGG CCG GTC TTC ACA AAG G & AGG TGG CGA TGA CGAAGT TGG G \\
\hline
\end{tabular}

for their efficiency using $10^{(-1 / \text { slope })}-1$ and we obtained slopes between -3.23 and -3.18 (92-94\% efficiency). Output of the qRTPCR was on log scale and corrected for drift with the threshold being set at $500 \mathrm{~nm}$. Data were analyzed using the $2^{-\Delta \Delta C T}$ method (Livak \& Schmittgen, 2001) with mRNA levels normalized to the housekeeping gene rpl6 since amplification efficiency for this gene was $94 \%$ and its expression did not change with experimental conditions.

\section{Enzyme activity}

Activity of PG enzyme was measured according to the rate of increase of reducing sugars using arsenomolybdate-copper reagent using D-galacturonic acid as a standard as described by (Vinokurov et al., 2014). This method is based on the measurement of the rate of increase of reducing groups (D-galacturonic acid) as a result of hydrolytic cleavage of polygalacturonic acid (substrate) by PG in supernatant. Color development indicative of D-galacturonic acid released and its stabilization is with arsenomolybdate reagent. Ten insect salivary gland pairs per sample were homogenized in $50 \mathrm{mM}$ phosphate buffer. Supernatant from a $600 \mathrm{~g}$ centrifugation step was used for further processing. The protein content of the supernatant was estimated using bicinchoninic acid reagent (Pierce, Rockford, IL) and bovine serum albumin as a standard (Smith et al., 1985). Enzyme supernatant was mixed with polygalacturonic acid solution (Sigma Aldrich, St. Louis, MO) $(0.5 \%$ in a $50 \mathrm{mM}$ sodium acetate buffer, $\mathrm{pH} 5.0)$ and added to tubes of both samples and standards, and equilibrated to $30^{\circ} \mathrm{C}$ for $10 \mathrm{~min}$. All tubes were vortexed and incubated for $10 \mathrm{~min}$ at $30^{\circ} \mathrm{C}$ and a $\mathrm{Cu}$-alkaline reagent was added to stop the reaction and tubes were heated for $15 \mathrm{~min}$ at $95^{\circ} \mathrm{C}$. Finally, an arsenomolybdate reagent was added to develop and stabilize the color and tubes were vortexed followed by centrifugation at 6000 g. $100 \mu \mathrm{l}$ of supernatant was pipetted in triplicate into wells of a 96-well microtiter plate and absorbance was read at $540 \mathrm{~nm}$ in a BioTek Synergy H1 multi-mode plate reader (Biotek, Winooski, VT). PG activity was expressed as units of D-galacturonic acid released per min per mg of protein.

\section{Statistical analyses}

Statistical analyses of all experiments were performed in SAS 9.3 using the Proc Glimmix procedure (SAS Institute Inc., Cary, NC). Data for all gene expression experiments were log transformed to meet the assumptions of equal variance. The Kenward-Roger method was used to calculate degrees of freedom (Kenward \& Roger, 1997). Expression of a particular gene was quantified relative to the expression of that particular gene from salivary glands of a colony reared on artificial diet (which was set as 1). Data points that failed to amplify or exhibited irregular amplification (standard deviation $>0.5$ ) among the technical replicates of each sample were eliminated prior to data analysis, as per instructions of the program manufacturer (available from www.lifetechnologies.com).

For the laboratory colony sex and age comparisons experiment, the interactions of sex (male and female), PG gene (LlPG1, $L I P G 2, L I P G 3$ ), and age (one, five, ten, and fifteen days old) were analyzed for interactions and main effects. Replicate was used as a random factor. For the laboratory colony adult and nymphal comparison experiment, replicate (day sampled) was used as the random factor.. Developmental stage of the insects and PG genes were analyzed for interactions and main effects.

For the 2012 wild collected L. lineolaris study, replicate (location within a region) was used as a random factor. Region (Delta and Hills), host (cotton, horseweed, and pigweed), and gene (LlPG1, LlPG2, and LlPG3) were analyzed for main effects and interactions. Data for each gene were analyzed for normality of distribution and one data point was removed because it was more than three standard deviations from the predicted value estimated by the statistical procedure. There was insufficient data to evaluate a year effect in the 2013-2014 wild collected L. lineolaris experiment, thus replicate, year, and replicate (year) were initially used as the random factors. Clover was only present for samples from the Hills region, thus clover was removed from the analyses. For initial analyses of gene expression, region (Delta and Hills), host (cotton, fleabane, horseweed, and pigweed), type (male, female, and nymph), and gene (LlPG1, LlPG2, LlPG3) were analyzed for interaction and effects. Region as a main effect and in interactions was never significant (Table 2), therefore region was removed from the fixed effects statement and the factors region and region*replicate (year) were added to the random statement. Since region was no longer a factor being examined, data for clover was placed back in the dataset and host, type, and gene were analyzed for effects and interaction. Data were analyzed for normality of distribution and two data points were removed because they occurred outside of three standard deviations from the predicted value estimated by the statistical procedure.

Polygalacturonase enzyme activity in the 2013-2014 wild collected L. lineolaris study was also compared. Again, there was insufficient data to make any comparisons between years, thus initially replicate, year, and replicate (year) were used as random factors. Again, clover was removed from the analysis since it was found only in the Hills region. Initial analyses revealed no effect of region (Table 2), therefore region was removed from the fixed effects statement, clover was placed back into the analysis, and region and region*replicate (year) were added to the random statement. Host and type were analyzed for interactions and main effects.

\section{RESULTS}

\section{Comparison of polygalacturonase gene expression based on sex and age}

The interaction of sex and age had a significant effect on the average overall gene expression (Table 2). The sex and age interaction revealed differences in average overall PG expression between sexes at individual ages as well as differences within a sex at different ages (Fig. 2). Average overall expression of PG was higher in one-day-old females than in one-day-old males; however, expression was higher in five-day-old males than five-day-old females. Average overall expression significantly decreased between one-day-old and five-days-old females but remained steady thereafter. Average overall expression significantly increased in males between one-day-old and five-day-old, 
Table 2. F-statistics for all experiments.

\begin{tabular}{|c|c|c|c|}
\hline \multicolumn{4}{|c|}{ Sex and age gene expression comparisons } \\
\hline & df & $\mathrm{F}$ & $\mathrm{p}$ \\
\hline sex $^{*}$ gene*age & 6,46 & 0.34 & 0.91 \\
\hline gene*age & 6,52 & 0.32 & 0.92 \\
\hline sex*gene & 2,52 & 0.47 & 0.63 \\
\hline sex*age & 3,52 & 10.30 & $<0.01$ \\
\hline sex & 1,52 & 0.04 & 0.84 \\
\hline age & 3,52 & 2.22 & 0.10 \\
\hline gene & 2,52 & 16.82 & $<0.01$ \\
\hline \multicolumn{4}{|c|}{ Nymph and adult gene expression comparisons } \\
\hline & df & $\mathrm{F}$ & $\mathrm{p}$ \\
\hline stage* gene & $4,38.99$ & 0.76 & 0.56 \\
\hline stage & $2,43.05$ & 0.70 & 0.50 \\
\hline gene & $2,42.99$ & 20.56 & $<0.01$ \\
\hline \multicolumn{4}{|c|}{2012 gene expression from wild L. lineolaris } \\
\hline & df & $\mathrm{F}$ & $\mathrm{p}$ \\
\hline region*host*gene & $4,61.93$ & 1.26 & 0.30 \\
\hline host $^{*}$ gene & $4,65.83$ & 0.75 & 0.56 \\
\hline region*gene & $2,65.64$ & 2.76 & 0.07 \\
\hline region*host & $2,72.20$ & 5.36 & $<0.01$ \\
\hline host & $2,71.77$ & 1.26 & 0.29 \\
\hline gene & $2,71.86$ & 13.41 & $<0.01$ \\
\hline \multicolumn{4}{|c|}{ 2013-2014 gene expression from wild $L$. lineolaris } \\
\hline Effects of region & df & $\mathrm{F}$ & $\mathrm{p}$ \\
\hline region*host*type*gene & $12,380.6$ & 0.35 & 0.98 \\
\hline$t^{*}$ gene & $6,393.9$ & 0.31 & 0.93 \\
\hline host*type & $6,400.9$ & 1.35 & 0.23 \\
\hline$n^{*}$ type*gene & $4,380.7$ & 0.60 & 0.66 \\
\hline pe & $2,438.5$ & 1.66 & 0.19 \\
\hline ost & 3,438 & 0.37 & 0.78 \\
\hline *gene & $2,426.9$ & 2.61 & 0.07 \\
\hline region & 1,456 & 0.03 & 0.90 \\
\hline \multicolumn{4}{|c|}{ Effects with region in random statement } \\
\hline host*type*gene & $16,484.9$ & 0.41 & 0.98 \\
\hline type*gene & $4,500.7$ & 1.75 & 0.14 \\
\hline he & $8,500.9$ & 6.68 & $<0.01$ \\
\hline host*type & $8,516.8$ & 2.02 & 0.04 \\
\hline \multicolumn{4}{|c|}{ 2013-2014 enzyme activity from wild L. lineolaris } \\
\hline Effects of region & df & $\mathrm{F}$ & \\
\hline region*type*host & $5,107.1$ & 0.54 & 0.74 \\
\hline region*type & $2,112.1$ & & 0.37 \\
\hline region*host & $3,115.6$ & 0.85 & 0.47 \\
\hline region & $1,126.6$ & & 0.66 \\
\hline \multicolumn{4}{|c|}{ Effects with region in random statement } \\
\hline host*type & $7,118.1$ & 0.75 & 0.63 \\
\hline & $2,125.8$ & 0.06 & 0.94 \\
\hline host & $4,127.5$ & 1.88 & 0.11 \\
\hline
\end{tabular}

but returned to a level similar to that in one-day-old males. The expression of individual genes was significantly different (Table 2) with expression of LlPG1 higher than ex-

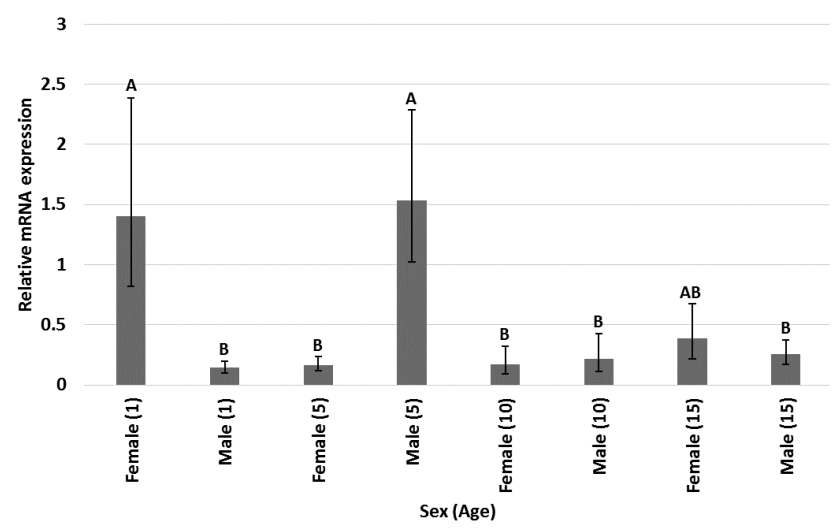

Fig. 2. Back-transformed mean and standard error of the total relative polygalacturonase gene expression of reared $L$. lineolaris from the study of age and sex. Columns followed by the same letter are not significantly different (Fisher's LSD, $\alpha=0.05$ ). $N=9$ for all treatments. Age is the number of days after adult eclosion.

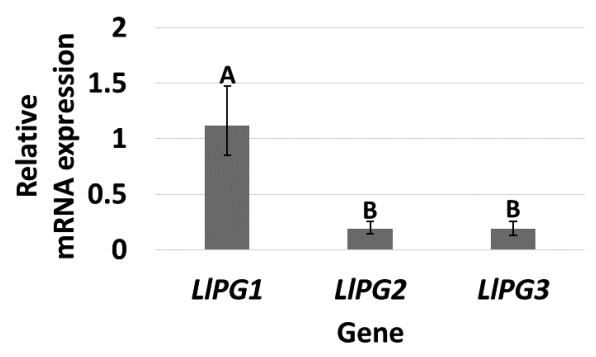

Fig. 3. Back-transformed mean and standard error of the expression of polygalacturonase genes in reared $L$. lineolaris in the study of age and sex. Columns with the same letter are not significantly different (Fisher's LSD, $\alpha=0.05$ ). $\mathrm{N}=24$ for each gene.

pression of LlPG2 or LlPG3 (Fig. 3). Data indicate that average overall $\mathrm{PG}$ expression is different between males and females at specific points during aging.

\section{Comparison of polygalacturonase gene expression between nymphs and adults}

The average overall expression of PG was not significantly different between adults of either age and nymphs (Table 2). The expression of individual genes was significantly different (Table 2) with the expression of LlPG1 significantly higher than expression of LlPG2 and LlPG3 (Fig. 4). These data indicate significant differences between expression of individual genes but do not reveal any differences in average overall gene expression at different ages or developmental stages.

\section{Polygalacturonase gene expression from 2012 field collections}

The interaction of region and host had a significant effect (Table 2) on overall gene expression. The average overall PG expression for L. lineolaris collected from cotton was significantly higher for those collected from the Hills compared to those collected from the Delta (Fig. 5), and the average overall PG expression in L. lineolaris collected from the Delta was significantly higher for those collected from horseweed than from cotton (Fig. 5). Overall, expression of LlPG1 was significantly higher than expression of LIPG2 and LlPG3 (Table 2, Fig. 6). These data indicate there are differences between individual genes, as well as regional and host differences in average overall gene expression.

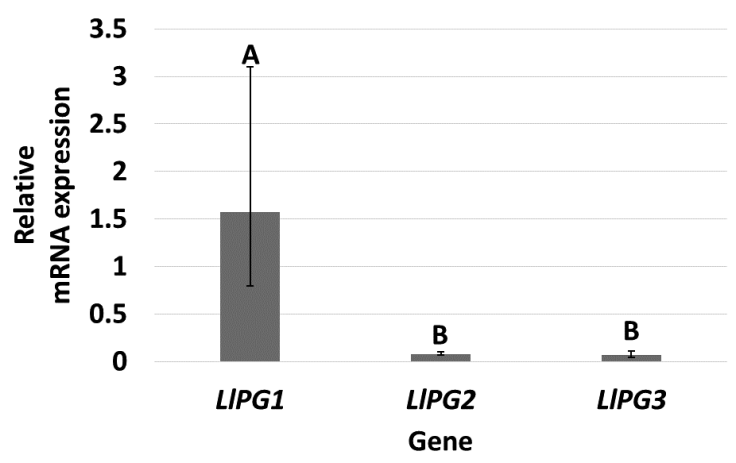

Fig. 4. Back-transformed mean and standard error of the expression of polygalacturonase genes in L. lineolaris in the study of nymphs and adults. Columns with the same letter are not significantly different (Fisher's LSD, $\alpha=0.05$ ). $\mathrm{N}=17$ for LIPG1 and LIPG2 and $\mathrm{N}=16$ for LIPG3. 


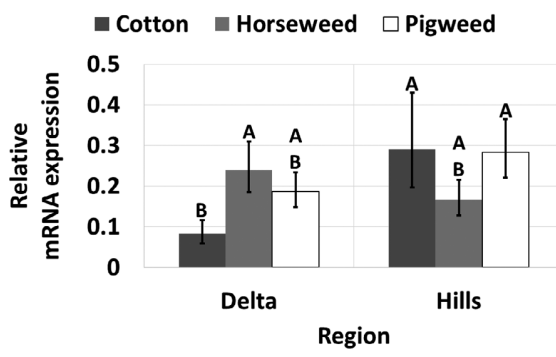

Fig. 5. Back-transformed mean and standard error of the effects of host and region on the expression of the average of the three PG genes in wild $L$. lineolaris in 2012. Columns with the same letter are not significantly different (Fisher's LSD, $\alpha=0.05$ ). $\mathrm{N}=14$ for Delta cotton (G. hirsutum) and horseweed (C. canadensis), $\mathrm{N}=13$ for Delta pigweed (Amaranthus sp.) and Hills cotton, and $\mathrm{N}=15$ for Hills horseweed and pigweed.

\section{Polygalacturonase gene expression and activity from 2013-2014 field collections}

The interaction of host and gene and host and type (nymph or adult) had a significant effect on PG expression (Table 2). There was not a gene that appeared to be the highest expressed gene for $L$. lineolaris collected from cotton; however, the relative expression of individual genes was significantly different within all the other hosts (Fig. 7). Generally, the average overall expression of PG was significantly higher for males and females than for nymphs but expression between males and females was never different (Fig. 8). There were no significant effects or interactions in regards to activity of PG enzyme (Table 2, 3). These data indicate that there are individual genes that are more important for some host plants than others, expression is higher in adults than nymphs, and PG enzyme activity is similar amongst hosts.

\section{DISCUSSION}

Data from laboratory reared insects revealed significant differences in PG expression between sexes, with age, and between individual PG genes. These results were anticipated based on data from Allen \& Mertens (2008) and Walker $\&$ Allen (2010). It was not possible to know the age of wild collected insects, thus the laboratory data may help explain the variation in wild collected $L$. lineolaris. How-

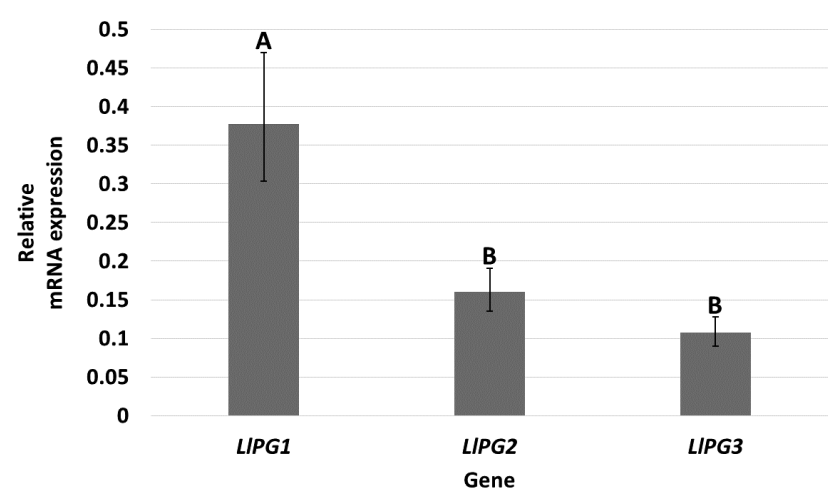

Fig. 6. Back-transformed mean and standard error of the expression of polygalacturonase genes in wild L. lineolaris in 2012 averaged across all hosts. Columns with the same letter are not significantly different (Fisher's LSD, $\alpha=0.05$ ). $N=30$ for $L I P G 1, N=28$ for LIPG2, and $\mathrm{N}=26$ for LIPG3.

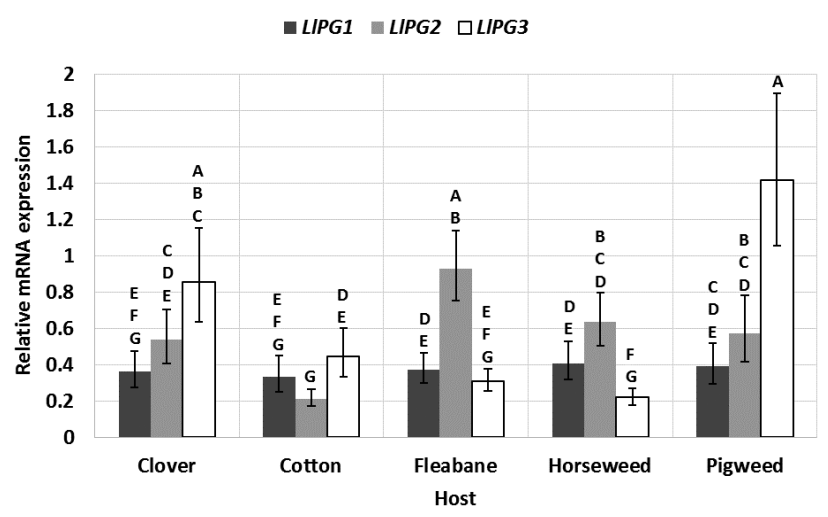

Fig. 7. Back-transformed mean and standard error of the effects of host on relative polygalacturonase gene expression in wild collected L. lineolaris from Mississippi during 2013-2014. Columns with the same letter are not significantly different (Fisher's LSD, $\alpha=$ 0.05). $\mathrm{N}=31$ for clover ( $T$. incarnatum), $\mathrm{N}=29$ for cotton ( $G$. hirsutum), $\mathrm{N}=58$ for fleabane (Erigeron sp.), $\mathrm{N}=45$ for horseweed ( $C$. canadensis), and $\mathrm{N}=34$ for pigweed (Amaranthus sp.). $\mathrm{N}$ ranged from 29 to 58 for LIPG1, 27 to 52 for LIPG2, and 27 to 53 for LIPG3.

ever, sex can be accounted for, thus sex was included as a factor in the 2013-2014 wild collected L. lineolaris study. Comparisons of PG expression in laboratory reared adults and nymphs were found not to be significantly different in our study, but we assumed that the possibility existed for more stable PG expression in nymphs than adults in wild populations because nymphs predominantly feed on one host while adults are capable of changing hosts (MacCreary, 1965; Kumar \& Musser, 2009) thus data from wild collected nymphs may have less variation than adults. For this reason nymphs were also collected for the 2013-2014 wild collected L. lineolaris study. Data from our laboratory colony experiments revealed that consideration must be given to age and sex when planning and implementing PG experiments.

Data from the two experiments using wild collected L. lineolaris revealed differences in average overall PG expression between hosts, differences in individual gene expres-

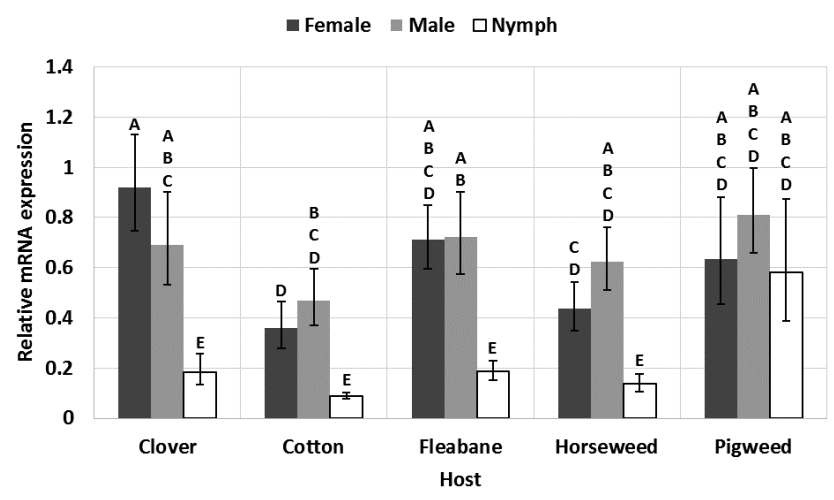

Fig. 8. Back-transformed mean and standard error of the effects of host on type (sex/developmental stage) on relative total polygalacturonase gene expression in wild $L$. lineolaris collected from Mississippi during 2013-2014. Columns with the same letter are not significantly different (Fisher's LSD, $\alpha=0.05$ ). $\mathrm{N}$ ranged from 24 to 37 for clover ( $T$. incarnatum), 14 to 35 for cotton (G. hirsutum), 44 to 68 for fleabane (Erigeron sp.), 28 to 53 for horseweed (C. canadensis), 27 to 37 for pigweed (Amaranthus sp.), 35 to 68 for females, 28 to 44 for males, and 14 to 51 for nymphs. 
Table 3. Mean and standard error (SE) of polygalacturonase enzyme activity in wild collected populations of $L$. lineolaris from Mississippi during 2013-2014.

\begin{tabular}{lccc}
\hline Host & $\mathrm{N}$ & Mean $^{1}$ & $(\mathrm{SE})$ \\
\hline Clover (T. incarnatum) & 19 & 0.42 & $(0.02)$ \\
Cotton (G. hirsutum) & 15 & 0.35 & $(0.03)$ \\
Fleabane (Erigeron sp.) & 45 & 0.38 & $(0.01)$ \\
Horseweed (C. canadensis) & 29 & 0.34 & $(0.02)$ \\
Pigweed (Amaranthus sp.) & 30 & 0.35 & $(0.02)$ \\
\hline
\end{tabular}

${ }^{1}$ Expressed in units of D-galacturonic acid released per mg of protein.

sion within hosts, and differences in average overall gene expression between males and females versus nymphs within hosts. These differences were expected based on laboratory data as well as data from Allen \& Mertens (2008) and Walker \& Allen (2010). Our data did not indicate that any particular gene was most important for $L$. lineolaris feeding on cotton. Based on the discovery of additional genes by Showmaker et al. (2016) and Zhu et al. (2016), more research is needed to identify any genes that may be most important in L. lineolaris feeding on cotton.

Wild collected males and females did not express PG differently but had higher overall PG expression than nymphs collected from all hosts except pigweed. One explanation for this may be that adults need higher levels of PG genes ready to be translated to protein in the event that a host change is necessary, while nymphs would not normally be able to change host plants, thus requiring lower levels of PG. The lower expression of PG in nymphs could make nymphs a more suitable target than adults for PGIP or dsRNA crop based control strategies. The lower expression of PG genes in nymphs could be easier to inhibit with lower expression of PGIP or dsRNA in genetically modified plants.

The lack of significant differences in total PG enzyme activity reveals that probably the endo- or exo-PG activity (Celorio-Mancera et al., 2009) may be a better indicator of changes in activity dependent upon host. This indicates, in light of the gene expression data, that the genes may be encoding for different kinds of PG activity that may not be reflective in total activity. Our enzyme assay was only able to look at the total amount of PG enzyme activity through the measurement of release of D-galacturonic acid and does not distinguish between endo and exo- polygalacturonases. Some research has indicated that there are multiple isoenzymes or proteins of PG in some PG expressing organisms, including L. lineolaris (Agblor et al., 1994; De Lorenzo et al., 2001; Poinssot et al., 2003; Shackel, et al., 2005; Celorio-Mancera et al., 2009). Based on this information it may be that each PG gene translates a specific isoenzyme (either endo- or exo) for use on a specific host, thus the expression of PG genes and the concentrations of either exo- or endo- PG activity would vary on hosts, whereas total concentration of PG enzyme would not vary. More research in this area could be useful for discovering the functions of PG genes and their precise role in the specific type of PG activity expressed.

The primary hypothesis of this research was that a potential biotype or sibling species of $L$. lineolaris with an enhanced ability to feed on cotton may exist in the Mississippi Delta. Regional differences were found in the initial 2012 study, but in the larger study conducted during 2013 and 2014 no differences were discovered, indicating that populations of $L$. lineolaris have not selected with the ability to more effectively feed on cotton in areas such as the Mississippi Delta with a large proportion of the landscape planted in cotton. The increased damage to cotton and larger populations of L. lineolaris in the Delta compared to the Hills may be due to insecticide resistance. Fleming et al. (2015a) found higher levels of esterase enzymes in Delta populations of L. lineolaris, indicating that Delta populations of $L$. lineolaris may have selected for higher levels of insecticide resistance through increased expression of detoxifying enzymes. Insecticide resistance does not fully explain the difference given the results of Adams (2014) who found that L. lineolaris from the Delta developed faster on cotton than populations from the Hills and that Delta $L$. lineolaris had higher fecundity than those from the Hills. More research is needed to further explore the ecological and physiological differences in these populations and gain a better understanding of the physiological ecology of $L$. lineolaris.

In summary, expression of PG genes can be affected by host, developmental stage, age, and sex. These potential sources of variation need to be considered before implementing PG experiments. Developmental stage, age, and sex should be used as factors in experiments when appropriate. Region did not have a consistently significant effect on PG gene expression. Based on the results of this study, we propose that the three genes studied may not be reflective of the entire polygalacturonase enzyme system and may not be solely responsible in the adaptation of a suspected cotton biotype or sibling species shift toward host preference of cotton in the Mississippi Delta region. Host has a strong effect on expression of all three PG genes evaluated in this study; however, none of the genes stood out as the most important to L. lineolaris feeding on cotton. More research is needed to understand the PG system and the potential to target the system with genetically modified plants expressing specific PGIP or dsRNA.

ACKNOWLEDGEMENTS. Thanks to K. Knighten and the many student workers who maintained the rearing facilities and colonies. Thanks to E. Meadows, S. Ford, E. Ousterhout, and C. Henson for technical assistance in preparing samples for analysis. Thanks to J. MacGown for supplying the figure of the Mississippi geographic regions. Partial funding for this research was provided by USDA-ARS Specific Cooperative Agreement 58-6402-3-017.

DISCLOSURE. The authors declare that no conflict of interest exists.

\section{REFERENCES}

Adams B., Gore J., Catchot A., Musser F. \& Dodds D. 2014: A biological comparison of tarnished plant bug (Hemiptera: Miridae) populations from Mississippi's major agricultural regions. —Environ. Entomol. 43: 782-786. 
Agblor A., Henderson H.M. \& Madrid F.J. 1994: Characterisation of alpha-amylase and polygalacturonase from Lygus spp. (Heteroptera: Miridae). - Food. Res. Int. 27: 321-326.

Akhgari A.B., Motallebi M. \& Zamani M.R. 2012: Bean polygalacturonase-inhibiting protein expressed in transgenic Brassica napus inhibits polygalacturonase from its fungal pathogen Rhizoctonia solani. - Plant. Prot. Sci. 48: 1-9.

Allen M.L. 2007: Expressed sequenced tags from Lygus lineolaris (Hemiptera: Miridae), the tarnished plant bug. - Genet. Mol. Res. 6: 206-213.

Allen M.L. \& Mertens J.A. 2008: Molecular cloning and expression of three polygalacturonase cDNAs from the tarnished plant bug, Lygus lineolaris. - J. Insect Sci. 8: 27, 15 pp.

Baum J.A., Bogaert T., Clinton W., Heck G.R., Feldmann P., Ilagan O., Johnson S., Plaetinck G., Munyikwa T., Pleau M., VAughn T. \& Roberts J. 2007: Control of coleopteran insect pests through RNA interference. - Nat. Biotechnol. 25: 1322 1326.

Bautista M.A.M., Miyata T., Miura K. \& Tanaka T. 2009: RNA interference-mediated knockdown of a cytochrome P450, $C Y$ $P 6 B G 1$, from the diamondback moth, Plutella xylostella, reduces larval resistance to permethrin. - Insect Biochem. Mol. Biol. 39: 38-46.

Bergmann C.W., Ito Y., Singer D., Albersheim P., Darvill A.G., Benhamou N., Nuss L., Salvi G., Cervone F. \& de Lorenzo G. 1994: Polygalacturonase-inhibiting protein accumulates in Phaseolus vulgaris L. in response to wounding, elicitors and fungal infection. - Plant J. 5: 625-634.

Celorio-Mancera M.D., Allen M.L., Powell A.L., Ahmadi H., Salemi M.R., Phinney B.S., Shackel K.A., Greve L.C., Teuber L.R. \& LABAVITCH J.M. 2008: Polygalacturonase causes Lyguslike damage on plants: cloning and identification of western tarnished plant bug (Lygus hesperus) polygalacturonases secreted during feeding. - Arthropod-Plant Interact. 2: 215-225.

Celorio-Mancera M.D., Greve L.C., Teuber L.R. \& Labovitch J.M. 2009: Identification of endo- and exo-polygalacturonase activity in Lygus hesperus (Knight) salivary glands. - Arch. Insect Biochem. Physiol. 70: 122-135.

Cervone F., De Lorenzo G., Degra L., Salvi G. \& Bergami M. 1987: Purification and characterization of a polygalacturonaseinhibiting protein from Phaseolus vulgaris L. - Plant Physiol. 85: 631-637.

COHEN A.C. 2000: New oligidic production diet for Lygus hesperus Knight and L. lineolaris (Palisot de Beauvois). - J. Entomol. Sci. 35: 301-310.

D’Ovidio R., Raiola A., Capodicasa C., Devoto A., Pontiggia D., Roberti S., Galletti R., Conti E., O’Sullivan D. \& De LORENZO G. 2004: Characterization of the complex locus of bean encoding polygalacturonase-inhibiting proteins reveals subfunctionalization for defense against fungi and insects. Plant Physiol. 135: 2424-2435.

De Lorenzo G., D’Ovidio R. \& Cervone F. 2001: The role of polygalacturonase-inhibiting proteins (PGIPs) in defense against pathogenic fungi. - Annu. Rev. Phytopathol. 39: 313-335.

Ferrari S., Sella L., Janni M., De Lorenzo G., Favaron F. \& D'Ovidio R. 2011: Transgenic expression of polygalacturonase-inhibiting protein in Arabidopsis and wheat increases resistance to the flower pathogen Fusarium graminearum. Plant Biol. 14: 31-38.

Fleming D.E., Krishnan N., CATChot A.L. \& Musser F.R. 2015a: Susceptibility to insecticides and activities of glutathione Stransferase and esterase in populations of Lygus lineolaris (Hemiptera: Miridae) in Mississippi. - Pest. Manag. Sci. 72: 1595-1603.
Fleming D.E., Roehrdanz R.L., Allen K.C. \& Musser F.R. 2015b: Comparisons of Lygus lineolaris (Hemiptera: Miridae) from two distinct geographical regions of Mississippi. - Environ. Entomol. 44: 898-906.

Fry J., Xian G., Jin S., Dewitz J., Homer C., Yang L., Barnes C., Herold N. \& Wickham J. 2011: Completion of the 2006 National Land Cover Database for the conterminous United States. - PE \& RS 77: 858-864.

Joubert D.A., Slaughter A.R., Kemp G., Becker J.V.W., Krooshof G.H., Bergmann C., Benen J., Pretorius I.S. \& Vivier M.A. 2006: The grapevine polygalacturonase-inhibiting protein (VvPGIP1) reduces Botyrtis cinerea susceptibility in transgenic tobacco and differentially inhibits fungal growth. Transgenic Res. 15: 687-702.

Kenward M.G. \& Roger J.H. 1997: Small sample inference for fixed effects from restricted maximum likelihood. — Biometrics 53: 983-997.

Kumar A. \& Musser F.R. 2009: Intra and inter-crop movement of tarnished plant bug. In: Proceedings of Beltwide Cotton Conferences (January 5-8, 2009), San Antonio, TX. National Cotton Council, Memphis, TN. URL: http://www.cotton.org/ beltwide/proceedings.

LivaK K.J. \& Schmittgen T.D. 2001: Analysis of relative gene expression data using real-time quantitative PCR and the $2^{-\Delta \Delta C T}$ method. - Methods 25: 402-408.

MACCREARY D. 1965: Flight range observations on Lygus lineolaris and certain other Hemiptera. - J. Econ. Entomol. 58: 1004-1005.

MaO Y.-B., CaI W.-J., Wang J.-W., Hong G.-J., TAO X.-Y., WANG L.-J., HuAnG Y.-P. \& CHEN X.-Y. 2007: Silencing a cotton bollworm P450 monooxygenase gene by plant-mediated RNAi impairs larval tolerance of gossypol. - Nat. Biotechnol. 25: 1307-1313.

Miles P.W. 1972: The saliva of Hemiptera. - Adv. Insect Physiol. 9: 183-255.

Poinssot B., Vandelle E., Bentejac M., Adrian M., Levis C., Brygoo Y., Garin J., Sicilia F., Coutos-Thevenot P. \& Pugin A. 2003: The endopolygalacturonase 1 from Botrytis cinerea activates grapevine defense reactions unreleated to its enzymatic activity. - Mol. Plant-Microbe Int. 20: 411-419.

Powell A.L.T., van Kan J., ten Have A., Visser J., Greve L.C., Bennett A.B. \& Labavitch J.M. 2000: Transgenic expression of pear PGIP in tomato limits fungal colonization. - Mol. Plant-Microbe Int. 13: 942-950.

Schun R.T. \& Slater J.A. 1995: True Bugs of the World. Cornell University Press, Ithaca, NY, 336 pp.

Shackel K.A., Celorio-Mancera M.D.L.P., Ahmadi H., Greve L.C., Teuber L.R., Backus E.A. \& Labavitch J.M. 2005: Micro-injection of Lygus salivary gland proteins to simulate feeding damage in alfalfa and cotton flowers. - Arch. Insect Biochem. Physiol. 58: 69-83.

Showmaker K.C., Bednáǩ́ová A., Gresham C., Hsu C.-Y., PeterSON D.G. \& KRISHNAN N. 2016: Insight into the salivary gland transcriptome of Lygus lineolaris (Palisot de Beauvois). PLOS ONE 11: e0147197, 22 pp.

Smith P.K., Krohn R.I., Hermanson G.T., Mallia A.K., Gartner F.H., Provenzano M.D., Fujmoto E.K., Goeke N.M., Olson B.J. \& KLENK D.C. 1985: Measurement of protein using bicinchoninic acid. - Anal. Biochem. 150: 76-85.

Strong F.E. \& Kruitwagen E. 1970: Gustatory discrimination between meridic diets by the bug, Lygus hesperus. - J. Insect Physiol. 16: 521-530.

Strong F.E. \& Kruitwagen E.C. 1968: Polygalacturonase in the salivary apparatus of Lygus hesperus (Hemiptera). - J. Insect Physiol. 14: 1113-1119. 
Toubart P., Desiderio A., Salvi G., Cervone F., Daroda L. \& De LoRENZO G. 1992: Cloning and characterization of the gene encoding the endopolygalacturonase-inhibiting protein (PGIP) of Phaseolus vulgaris L. - Plant J. 2: 367-373.

Vinokurov K., Bednarova A., Tomcala A., Staskova T., KRISHNAN N. \& KoDRIK D. 2014: Role of adipokinetic hormone in stimulation of salivary gland activities: the fire bug Pyrrohcoris apterus L. (Heteroptera) as a model species. - J. Insect Physiol. 60: 58-67.

WALKeR W.B. \& Allen M.L. 2010: Expression and RNA interference of salivary polygalacturonase genes in the tarnished plant bug, Lygus lineolaris. - J. Insect Sci. 10: 173, 13 pp.

Williams M.R. 1986-2014: Cotton insect losses. URL: http:// www.entomology.msstate.edu/resources/cottoncrop.asp.

Williams M.R. 2012-2014: Cotton insect losses. URL: http:// www.entomology.msstate.edu/resources/cottoncrop.asp.

Zhang L., Xu P., Xiao H., Lu Y., Liang G., Zhang Y. \& Wu K. 2015: Molecular characterization and expression profiles of polygalacturonase genes in Apolygus lucorum (Hemiptera: Miridae). — PLoS ONE 10(5): e0126391, 12 pp.

Zhao Y., Yang G., Wang-Pruski G. \& You M. 2008: Phyllotera striolata (Coleoptera: Chrysomelidae): arginine kinase cloning and RNAi-based pest control. - Eur. J. Entomol. 105: 815-822.

Zhou X., Wheeler M.M., Oi F.M. \& Scharf M.E. 2008: RNA interference in the termite Reticulitermes flavipes through ingestion of double-stranded RNA. - Insect Biochem. Mol. Biol. 38: $805-815$.

Zhu Y.-C., Yao J. \& Luttrell R. 2016: Identification of genes potentially responsible for extra-oral digestion and overcoming plant defense from salivary glands of the tarnished plant bug (Hemiptera: Miridae) using cDNA sequencing. - J. Insect Sci. 16(1): 60, $11 \mathrm{pp}$.

Received July 26, 2016; revised and accepted November 11, 2016 Published online January 13, 2017 